Vol. 1 No. 4 Oktober 2021 e-ISSN : 2774-6283 | p-ISSN : 2775-0019

\title{
ANALISIS KEBIJAKAN PENGEMBANGAN SMK : STUDI PADA SMK NEGERI DAN SWASTA DI KOTA PONTIANAK
}

\author{
LANA ATMIM NUR \\ Pascasarjana PMIPA, Universitas Indraprasta PGRI, Jakarta \\ e-mail: lanaatmimnur@gmail.com
}

\begin{abstract}
ABSTRAK
Pemerintah melalui Kementerian Pendidikan Nasional telah merencanakan Program Pengembangan SMK yang salah satu diantaranya adalah dengan menambah jumlah SMK yang ada sehingga pada tahun 2014 diharapkan rasio jumlah SMK : SMA sebesar 67\% : 33\% sebagaimana tertuang dalam kebijakan Rencana Strategis Depdiknas 2010-2014. Penulis mencoba untuk meneliti tentang pengembangan Sekolah Menengah Kejuruan (SMK) di Kota Pontianak dengan mengambil data-data riil yang ada di lapangan dilihat dari aspek spektrum keahlian, pemenuhan delapan standar nasional pendidikan dan pemenuhan Sumber Daya Manusia yang lebih dikhususkan pada ketersediaan guru. Dari aspek-aspek tersebut nantinya dapat kita lihat apakah data-data riil yang sudah penulis dapatkan sesuai dengan kegiatan perekonomian kota Pontianak atau tidak. Hal ini dilakukan sebagai penulisan awal untuk kepentingan pengembangan SMK selanjutnya, misalnya untuk mempertimbangan jenis keahlian SMK yang akan dikembangkan. Penelitian ini menggunakan pendekatan penulisan kualitatif deskriptif. Instrumen yang digunakan dalam penulisan yaitu berupa lembar observasi yang sudah dibuat oleh Dikti. Lembar observasi ini berfungsi untuk mencatat data-data yang penulis temukan pada subjek penulisan meliputi kompetensi keahlian yang ada di SMK yang dikunjugi, akreditasi sekolah, dan profil guru. Data yang diperlukan pada penulisan ini diperoleh melalui observasi, wawancara dan studi dokumentasi. Hasil Penelitian didapati bahwa SMK dengan bidang keahlian bisnis dan manajemen mendominasi SMK yang ada di kota pontianak. Hal ini belum sejalan dengan kegiatan perekonomian dimana didominasi oleh sektor perdagangan, restoran dan hotel yang mestinya didukung penuh oleh SMK dengan bidang keahlian Seni, Kerajinan, dan Pariwisata. Selain itu terdata juga jumlah guru produktif sebanyak 314 guru yang mendukung pendidikan vokasi di Kota Pontianak
\end{abstract}

Kata Kunci: Pengembangan SMK, Kota Pontianak, Perekonomian

ABSTRACT
The government through the Ministry of National Education has planned a Vocational Development Program, one of which is to increase the number of existing SMKs so that in 2014 it is expected that the ratio of the number of SMKs: SMAs is 67\%: 33\% as stated in the 20102014 Ministry of National Education Strategic Plan policy. The author tries to research the development of Vocational High Schools (SMK) in Pontianak City by taking real data in the field seen from the aspect of the spectrum of expertise, the fulfillment of eight national education standards and the fulfillment of Human Resources which is more devoted to the availability of teachers. From these aspects, we can later see whether the real data that the author has obtained is in accordance with the economic activities of the city of Pontianak or not. This is done as an initial writing for the benefit of further vocational development, for example to consider the type of vocational expertise to be developed. This study uses a descriptive qualitative writing approach. The instrument used in writing is in the form of an observation sheet that has been made by Dikti. This observation sheet serves to record the data that the authors found on the subject of writing including the competence of skills in the visited vocational schools, school accreditation, and teacher profiles. The data needed in this paper were obtained through observation, interviews and documentation studies. The results of the study found that vocational schools with business and management expertise dominated the vocational schools in Pontianak city. This is not in line with economic activity which is dominated by the trade, restaurant and hotel sectors which should be fully supported by 
vocational schools with expertise in Arts, Crafts, and Tourism. In addition, there are also 314 productive teachers who support vocational education in Pontianak City

Keywords: Vocational Development Program, Pontianak City, Economics

\section{PENDAHULUAN}

Pendidikan nasional bertujuan untuk berkembangnya potensi peserta didik agar menjadi manusia yang beriman dan bertakwa kepada Tuhan Yang Maha Esa, berakhak mulia, sehat, berilmu, cakap, kreatif, mandiri, dan menjadi warga Negara yang demokratis serta bertanggung jawab.

Berdasarkan UU Sisdiknas No. 20 Tahun 2003, disebutkan bahwa jenjang pendidikan menengah terdiri atas Pendidikan Menengah Umum dan Pendidikan Menengah Kejuruan. Pendidikan Menengah Umum terdiri dari Sekolah Menengah Atas (SMA) dan Madrasah Aliyah (MA). Sedangkan Pendidikan Menengah Kejuruan terdiri dari Sekolah Menengah Kejuruan (SMK) dan Madrasah Aliyah Kejuruan (MAK) atau bentuk lain yang sederajat.

Pesatnya laju pertumbuhan industri di Indonesia, menuntut ketersediaan tenaga kerja yang terampil dan ahli sesuai dengan bidang keahlian yang dibutuhkan. Untuk mengimbangi kebutuhan dunia industri tersebut, maka Pemerintah melalui Kementerian Pendidikan Nasional (Kemdiknas) dituntut untuk menyiapkan tenaga-tenaga kerja yang siap untuk menjawab tantangan dunia industri tersebut.

Mencermati fenomena di atas, maka perlu kiranya Pemerintah lebih memperhatikan Pendidikan Menengah Kejuruan sebagai prioritas utama dalam menyiapkan tenaga-tenaga siap pakai yang dibutuhkan. Mengingat, Pendidikan Menengah Kejuruan merupakan pendidikan menengah yang mempersiapkan peserta didik terutama untuk bekerja dalam bidang tertentu.

Pemerintah harus memperhatikan semua aspek yang berhubungan dengan penambahan jumlah SMK di Indonesia supaya sekolah-sekolah baru yang didirikan di masing-masing wilayah sesuai dengan profil daerah masing-masing yang meliputi minat peserta didik, kegiatan perekonomian dan ketersediaan guru.

Salah satu daerah yang menarik untuk dicermati adalah Kota Pontianak. Ibukota propinsi Kalimantan Barat ini mengalami peningkatan jumlah penduduk yang cukup signifikan dalam kurun waktu 5 (lima) tahun terakhir periode 2004-2008 dimana pada tahun 2004 berdasarkan data dari Dinas Kependudukan dan Catatan Sipil Kota Pontianak jumlah penduduk yang tercatat sebanyak 478.740 jiwa dengan komposisi penduduk laki-laki sebanyak 246.829 jiwa atau 51,56\% sedangkan penduduk perempuan sebanyak 231.911 jiwa atau 48,44\%. Untuk tahun 2008 jumlah penduduk Kota Pontianak tercatat sebanyak 534.996 jiwa dengan komposisi penduduk laki-laki sebanyak 277.138 jiwa atau $51,80 \%$ dan penduduk perempuan sebanyak 266.858 jiwa atau $49,88 \%$.

Kegiatan perekonomian di kota Pontianak pada tahun 2004, sektor perdagangan, restoran \& hotel mempunyai kontribusi yang paling tinggi dalam memberikan kontribusinya yaitu sebesar 22,06 \% sedangkan untuk sektor listrik, gas dan air bersih adalah yang rendah dimana kontribusinya hanya sebesar $0,59 \%$. Untuk tahun 2008 sektor perdagangan, restoran \& hotel masih penyumbang tertinggi dalam memberikan kontribusinya dalam penyusunan struktur ekonomi Kota Pontianak dengan kontribusi sebesar 22,63 \% sedangkan sektor yang paling rendah dari keseluruhan sektor adalah sektor pertanian dimana memberikan kontribusinya hanya sebesar $0,54 \%$.

Untuk menunjang kegiatan perekonomian di kota Pontianak, maka dibutuhkan tenagatenaga kerja yang terampil agar kegiatan perekonomian dapat berjalan sebagaimana mestinya. Tenaga-tenaga kerja inilah yang harus dipersiapkan oleh sekolah kejuruan khususnya Sekolah Menengah Kejuruan. Sehingga penulis berfikir bahwa pengembangan SMK di Kota Pontianak harus segera dilaksanakn untuk manjawab tantangan industri.

Dari uraian di atas, penulis mencoba untuk meneliti tentang pengembangan Sekolah Menengah Kejuruan (SMK) di Kota Pontianak dengan mengambil data-data riil yang ada di lapangan dilihat dari aspek spektrum keahlian, pemenuhan delapan standar nasional pendidikan 


\section{Vol. 1 No. 4 Oktober 2021 e-ISSN : 2774-6283 | p-ISSN : 2775-0019}

dan pemenuhan Sumber Daya Manusia yang lebih dikhususkan pada ketersediaan guru. Dari aspek-aspek tersebut nantinya dapat kita lihat apakah data-data riil yang sudah penulis dapatkan sesuai dengan kegiatan perekonomian kota Pontianak atau tidak. Hal ini dilakukan sebagai penulisan awal untuk kepentingan pengembangan SMK selanjutnya, misalnya untuk mempertimbangan jenis keahlian SMK yang akan dikembangkan, jumlah guru yang dibutuhkan serta penambahan fasilitas yang sesuai dengan kebutuhan.

\section{METODE PENELITIAN}

Penelitian ini menggunakan pendekatan penulisan kualitatif deskriptif dengan karakteristik:

1. Dilakukan pada kondisi yang alamiah, (sebagai lawannya adalah eksperimen), langsung ke sumber data dan penulis adalah kunci.

2. Penelitian kualitatif lebih bersifat deskriptif. Data yang terkumpul berupa kata-kata atau gambar sehingga tidak menekankan pada angka.

3. Penelitian kualitatif lebih menekankan pada proses daripada produk atau outcome.

4. Penelitian kualitatif melakukan analisis data secara induktif.

5. Penelitian kualitatif lebih menekankan makna (data dibalik yang teramati).

Instrumen yang digunakan dalam penulisan yaitu berupa lembar observasi yang sudah dibuat oleh Dikti. Lembar observasi ini berfungsi untuk mencatat data-data yang penulis temukan pada subjek penulisan meliputi kompetensi keahlian yang ada di SMK yang dikunjugi, akreditasi sekolah, dan profil guru.

Data yang diperlukan pada penulisan ini diperoleh melalui observasi, wawancara dan studi dokumentasi. Observasi dan wawancara dilakukan untuk memperoleh data primer yang berkaitan dengan kompetensi keahlian yang dikembangkan oleh SMK di Kota Pontianak, akreditasi sekolah dan kesetersediaan SDM guru. Sedangkan studi dokumentasi dilakukan untuk memperoleh data sekunder penulisan berupa profil Kota Pontianak yang meliputi kegiatan perekonomian dan penyerapan tenaga kerja yang ada pengaruhnya terhadap perkembangan SMK di Kota Pontianak.

Analisis data yang dimaksud pada penulisan ini adalah pemerosesan data hasil observasi dan wawancara yang penulis isikan ke dalam lembar observasi berupa kompetensi keahlian yang dikembangakan oleh sekolah, akreditasi sekolah dan profil guru, serta hasil studi dokumentasi berupa data sekunder tentang profil wilayah.

Pada dasarnya proses analisis data akan dilakukan dengan menggunakan tahap-tahap sebagai berikut :

1. Data Reduction (reduksi data)

2. Data Display (Penyajian data)

3. Conclusion Drawing (Penarikan kesimpulan)

\section{HASIL DAN PEMBAHASAN}

\section{Hasil}

1. Bidang Studi Keahlian dan Kompetensi Keahlian

Berdasarkan hasil penulisan, jumlah SMK yang ada di Kota Pontianak sebanyak 25 SMK yang terdiri dari 7 SMK Negeri dan 18 SMK Swasta. Bidang studi keahlian yang banyak diselenggarakan di SMK di Kota Pontianak adalah bidang studi keahlian bisnis dan manajemen yang diselenggarakan di 12 sekolah. Bidang studi keahlian teknologi dan rekayasa diselenggarakan di 8 sekolah, kemudian bidang studi keahlian teknologi informasi dan komunikasi diselenggarakan di 7 sekolah. Bidang studi keahlian seni, kerajinan dan pariwisata diselenggarakan di 4 sekolah, dan sisanya adalah bidang studi keahlian kesehatan yang diselenggarakan di 1 sekolah, serta bidang studi keahlian agrobisnis dan agroteknologi yang juga diselenggarakan di 1 sekolah. Tabel berikut menggambarkan bidang studi keahlian yang diselenggarakan di kota Pontianak. 
VOCATIONAL : Jurnal Inovasi Pendidikan Kejuruan

Vol. 1 No. 4 Oktober 2021 e-ISSN : 2774-6283 | p-ISSN : 2775-0019

\section{Tabel 1. Spektrum SMK dan Bidang Keahliannya di Kota Pontianak}

\begin{tabular}{|c|c|c|c|c|}
\hline No & Nama SMK & Status & $\begin{array}{c}\text { Bidang Keahlian (BK) Yang } \\
\text { Diselenggarakan }\end{array}$ & $\begin{array}{c}\text { Total } \\
\text { BK }\end{array}$ \\
\hline 1 & SMK Negeri 6 Kota Pontianak & Negeri & $\begin{array}{l}\text { 1. Seni, Kerajinan dan } \\
\text { Pariwisata } \\
\text { 2. Teknologi Informasi dan } \\
\text { Komunikasi }\end{array}$ & 2 \\
\hline 2 & SMK Negeri 3 Kota Pontianak & Negeri & Bisnis dan Manajemen & 1 \\
\hline 3 & SMK PGRI Kota Pontianak & Swasta & Teknologi dan Rekayasa & 1 \\
\hline 4 & SMK Ethika Kota Pontianak & Swasta & Bisnis dan Manajemen & 1 \\
\hline 5 & SMK Negeri 4 Kota Pontianak & Negeri & $\begin{array}{l}\text { 1. Teknologi Informasi dan } \\
\text { Komunikasi } \\
\text { 2. Teknologi dan Rekayasa }\end{array}$ & 2 \\
\hline 6 & $\begin{array}{l}\text { SMK Al-Madani } \\
\text { Kota Pontianak }\end{array}$ & Swasta & $\begin{array}{l}\text { Teknologi Informasi dan } \\
\text { Komunikasi }\end{array}$ & 1 \\
\hline 7 & SMK Koperasi Kota Pontianak & Swasta & $\begin{array}{l}\text { 1. Teknologi Informasi dan } \\
\text { Komunikasi } \\
\text { 2. Bisnis dan Manajemen }\end{array}$ & 2 \\
\hline 8 & $\begin{array}{l}\text { SMK Bhineka Tunggal Ika } \\
\text { Kota Pontianak }\end{array}$ & Swasta & Bisnis dan Manajemen & 1 \\
\hline 9 & SMK Negeri 2 Kota Pontianak & Negeri & Teknologi dan Rekayasa & 1 \\
\hline 10 & SMK LKIA Kota Pontianak & Swasta & Bisnis dan Manajemen & 1 \\
\hline 11 & SMTI Kota Pontianak & Swasta & $\begin{array}{l}\text { 1. Teknologi dan Rekayasa } \\
\text { 2. Kesehatan }\end{array}$ & 2 \\
\hline 12 & $\begin{array}{l}\text { SMK Bina Utama } \\
\text { Kota Pontianak }\end{array}$ & Swasta & Teknologi dan Rekayasa & 1 \\
\hline 13 & $\begin{array}{l}\text { SMK Santa Maria } \\
\text { Kota Pontianak }\end{array}$ & Swasta & Bisnis dan Manajemen & 1 \\
\hline 14 & $\begin{array}{l}\text { SMK Kristen Immanuel } \\
\text { Kota Pontianak }\end{array}$ & Swasta & $\begin{array}{l}\text { 1. Teknologi Informasi dan } \\
\text { Komunikasi } \\
\text { 2. Bisnis dan Manajemen }\end{array}$ & 2 \\
\hline 15 & $\begin{array}{l}\text { SMK Cinta Bumi Khatulistiwa } \\
\text { Kota Pontianak }\end{array}$ & Swasta & $\begin{array}{l}\text { Seni, Kerajinan dan } \\
\text { Pariwisata }\end{array}$ & 1 \\
\hline 16 & $\begin{array}{l}\text { SMK Muhammadiyah } \\
\text { Kota Pontianak }\end{array}$ & Swasta & Bisnis dan Manajemen & 1 \\
\hline 17 & SMK Negeri 7 Kota Pontianak & Negeri & $\begin{array}{l}\text { 1. Teknologi Informasi dan } \\
\text { Komunikasi } \\
\text { 2. Teknologi dan Rekayasa }\end{array}$ & 2 \\
\hline 18 & SMK Mandiri Kota Pontianak & Swasta & Bisnis dan Manajemen & 1 \\
\hline 19 & SMK Negeri 5 Kota Pontianak & Negeri & $\begin{array}{l}\text { Seni, Kerajinan dan } \\
\text { Pariwisata }\end{array}$ & 1 \\
\hline 20 & $\begin{array}{l}\text { SMK Boedi Oetomo Kota } \\
\text { Pontianak }\end{array}$ & Swasta & Bisnis dan Manajemen & 1 \\
\hline 21 & $\begin{array}{l}\text { SMK Pelayaran Pembangunan } \\
\text { Kota Pontianak }\end{array}$ & Swasta & Teknologi dan Rekayasa & 1 \\
\hline 22 & $\begin{array}{l}\text { SMK Abdi Agape } \\
\text { Kota Pontianak }\end{array}$ & Swasta & Bisnis dan Manajemen & 1 \\
\hline 23 & $\begin{array}{l}\text { SMK Sultan Syarif } \\
\text { Abdurrahman Kota Pontianak }\end{array}$ & Swasta & $\begin{array}{l}\text { 1. Teknologi Informasi dan } \\
\text { Komunikasi } \\
\text { 2. Teknologi dan Rekayasa }\end{array}$ & 2 \\
\hline 24 & SMK Elim Kalimantan & Swasta & $\begin{array}{l}\text { Agribisnis dan Agroteknologi } \\
\text { 1. Bisnis dan Manajemen }\end{array}$ & 1 \\
\hline 25 & SMK Negeri 1 Kota Pontianak & Negeri & $\begin{array}{l}\text { 2. Seni, Kerajinan dan } \\
\text { Pariwisata }\end{array}$ & 2 \\
\hline & \multicolumn{3}{|c|}{$\begin{array}{c}\text { Pariwisata } \\
\text { Jumlah Bidang Studi Keahlian yang diselenggarakan }\end{array}$} & 33 \\
\hline
\end{tabular}




\section{Profil Guru}

Informasi yang tidak kalah pentingnya dari informasi-informasi di atas adalah informasi yang berkenaan dengan tenaga pendidik. Dalam hal ini, penulis memfokuskan pada guru-guru produktif (guru yang mengajar mata pelajaran keahlian).

Beberapa hal yang harus diperhatikan dalam mengembangkan SMK di suatu wilayah adalah ketersediaan guru. Salah satunya adalah dengan memperhatikan dan menganalisa usia guru yang ada saat ini, sehingga nantinya dapat diketahui jumlah guru yang akan pensiun dalam kurun waktu 10 hingga 15 tahun kedepan, serta jumlah guru yang masih berpotensi untuk melanjutkan studinya agar semua guru dapat memenuhi standar kualifikasi tenaga pendidik yang berlaku saat ini. Dalam penulisan ini, penulis membagi rentang usia guru dengan rentang 10 tahun yang dimulai dari umur 21 tahun hingga pada rentang umur 50 tahun dan lebih dari 50 tahun. Penulis juga membagi usia guru per bidang bidang studi keahlian agar dapat mengetahui guru dengan bidang studi keahlian manakah yang paling dibutuhkan dalam rentang per-10 tahun mendatang.

Tabel 2 Rentang Usia Guru Produktif di Kota Pontianak

\begin{tabular}{cc}
\hline Rentang Usia Guru & Jumlah \\
\hline $21-30$ Tahun & 88 Guru \\
$31-40$ Tahun & $101 \mathrm{Guru}$ \\
$41-50$ Tahun & $92 \mathrm{Guru}$ \\
$>50$ Tahun & $31 \mathrm{Guru}$ \\
Tidak Teridentifikasi (TT) & $2 \mathrm{Guru}$ \\
Jumlah Guru Produktif & $314 \mathrm{Guru}$
\end{tabular}

Berdasarkan tabel di atas, memperlihatkan bahwa mayoritas usia guru bidang produktif yang terdapat pada SMK di wilayah Kota Pontianak adalah pada rentang 31-40 tahun dengan jumlah 101 orang. Selanjutnya disusul dengan guru yang memiliki rentang usia 41-50 tahun dengan jumlah 92 orang dan 88 orang dengan rentang usia 21-30 tahun, serta 31 orang pada rentang usia di atas 50 tahun. Dengan melihat komposisi tersebut, maka dapat meningkatkan harapan akan kualitas peserta didik, mengingat pada kisaran usia 3140 tersebut merupakan usia produktif dari orang dalam berkarir. Kemudian, dengan banyaknya angkatan muda yang mengajar (rentang usia 21-30) dapat meningkatkan harapan akan kreatifitas dalam proses pembelajaran. Namun demikian, fakta yang perlu lebih dicermati oleh Pemerintah maupun pihak yang terkait dengan pendidikan (Kementerian Pendidikan Nasional) adalah jumlah 31 orang guru yang berada pada usia akan memasuki pensiun yaitu di atas 50 tahun. Angka ini walau tidak terlalu tinggi yaitu sekitar 10\% .Akan tetapi tentunya hal ini juga harus diperhatikan oleh Pemerintah agar tidak terjadi kekurangan guru untuk bidang produktif dalam jangka waktu 10 tahun mendatang.

Rentang usia guru berdasarkan masing-masing bidang studi keahlian yang diselenggerakan tentunya dapat menunjukkan dengan lebih terperinci sejauh mana potensi dan kebutuhan yang dimiliki dari masing-masing bidang studi keahlian yang ada di Kota Pontianak. Untuk itulah, penulis memerinci data tentang rentang usia guru produktif SMK berdasarkan masing-masing bidang studi keahlian yang diselenggarakan di Kota Pontianak.

Tabel 3. Rentang Usia Guru Produktif Berdasarkan Bidang Studi Keahlian

\begin{tabular}{clcccccc}
\hline \multirow{2}{*}{ No. } & Bidang Keahlian (BK) & \multicolumn{7}{c}{ Rentang Usia (Tahun) } \\
& Yang Diselenggarakan & $\mathbf{2 1 - 3 0}$ & $\mathbf{3 1 - 4 0}$ & $\mathbf{4 1 - 5 0}$ & $\mathbf{7 5 0}$ & \multirow{2}{*}{ TT } & \multirow{2}{*}{ Jumlah } \\
\hline 1 & Bisnis dan Manajemen & 40 & 39 & 33 & 13 & - & 125 \\
2 & Teknologi dan Rekayasa & 20 & 34 & 26 & 8 & 2 & 90 \\
3 & Seni, Kerajinan dan & 16 & 16 & 19 & 8 & - & 59
\end{tabular}


Vol. 1 No. 4 Oktober 2021 e-ISSN : 2774-6283 | p-ISSN : 2775-0019

\begin{tabular}{|c|c|c|c|c|c|c|c|}
\hline 4 & $\begin{array}{l}\text { Teknologi Informasi dan } \\
\text { Komunikasi }\end{array}$ & 7 & 8 & 12 & - & - & 27 \\
\hline 5 & Kesehatan & 2 & 4 & - & 2 & - & 8 \\
\hline 6 & $\begin{array}{l}\text { Agribisnis dan } \\
\text { Agroteknologi }\end{array}$ & 3 & - & 2 & - & - & 5 \\
\hline
\end{tabular}

Guru produktif pada SMK Bisnis dan Manajemen di Kota Pontianak didominasi oleh oleh guru yang berusia antara 21 - 30 tahun, yaitu sebesar 32\%. Kemudian diikuti guru yang berusia 31 - 40 sebesar 31\% dan guru yang berusia 41-50 tahun yang mencapai 26\%. Hal ini menandakan bahwa untuk bidang keahlian Bisnis dan Manajemen mayoritas guru-nya adalah berusia produktif, dan ini sangat besar manfaatnya bagi peserta didik. Guru produktif pada bidang keahlian ini yang akan memasuki usia pensiun besar persentasenya yaitu $11 \%$. Tentunya perhatian terhadap guru yang akan pensiun $5-10$ tahun yang akan datang pada bidang ini harus lebih diperhatikan agar sudah dipersiapkan pengganti/penambahan guru yang sesuai bidang keahlian ini.

Berdasarkan data di atas, terlihat bahwa mayoritas guru sebanyak 38\% guru bidang produktif pada SMK Teknologi dan Rekayasa yang berada di Kota Pontianak berusia antara 31-40 tahun. Dengan besarnya persentase pada usia produktif ini diharapkan mampu meningkatkan kualitas pembelajaran bagi peserta didik. Selanjutnya persentase atau besaran jumlah guru yang berusia antara 41-50 tahun sebesar 29\%. Untuk bidang ini jumlah guru yang akan memasuki usia pensiun berjumlah $9 \%$ dari guru yang ada. Untuk itu, bidang ini juga harus jadi perhatian mengingat persentase guru yang cukup banyak terlebih ditambah jumlah guru yang berada pada usia $41-50$. Hal tersebut tentunya akan memengaruhi kegiatan pembelajaran jika tidak diantisipasi mulai dari sekarang.

Bidang studi keahlian Seni, Kerajinan dan Pariwisata mayoritas gurunya berada pada usia $41-50$ tahun yang besarnya $32 \%$. Untuk bidang ini yang akan memasuki usia pensiun yaitu pada usia $>50$ tahun cukup besar yaitu $14 \%$, walaupun begitu nampaknya kekhawatiran akan kurangnya guru produktif pada bidang ini akan terjawab oleh guru-guru pada rentang usia yang lebih muda yaitu pada rentang usia 21-30 tahun dan 31-40 tahun yang masing-masing memiliki persentase yang sama yaitu sebesar 27\%. Akan tetapi, antisipasi dari instansi terkait perlu segera dilakukan untuk menambah jumlah guru produktif pada bidang ini agar tidak terjadi kekosongan guru.

Usia guru produktif pada bidang studi keahlian teknologi informasi dan komunikasi didominasi oleh usia antara 41-50 tahun sebesar 44\%, disusul oleh usia antara 31-40 tahun sebesar 30\% dan yang terakhir pada usia 21-30 tahunn yang mencapai $26 \%$. Pada bidang studi keahlian ini, tidak terdapat guru yang berusia di atas 50 tahun. Sehingga dalam kurun waktu 5 sampai 10 tahun mendatang kebutuhan guru pada bidang ini akan terpenuhi. Akan tetapi antisipasi awal perlu segera dilakukan, mengingat pada bidang ini didominasi oleh guru yang berusia antara 41-50 tahun. Berarti sekitar 15 hingga 20 tahun yang akan datang banyak guru pada bidang ini yang pensiun, sehingga perlu segera dilakukan regenerasi oleh instansi terkait

Bidang studi keahlian kesehatan hanya memiliki 8 orang guru produktif dengan rincian 50\% guru berusia antara 31-40 tahun, 25\% guru berusia antara 21-30 tahun serta guru yang akan pensiun sebesar $25 \%$. Data tersebut menunjukkan bahwa mayoritas guru pada bidang ini berada pada usia produktif sehingga diharapkan mampu meningkatkan kualitas pembelajaran bagi peserta didik. Hal yang perlu dicermati oleh instansi terkait adalah adanya $25 \%$ guru yang memasuki usia pensiun, sehingga perlu dilakukan regenerasi agar keperluan guru dapat terpenuhi.

Bila ditinjau dari jumlah guru produktif dan besaran persentasenya, maka bidang studi keahlian agrobisnis dan agroteknologi adalah bidang studi keahlian dengan jumlah guru paling sedikit yakni hanya sebanyak 5 orang. Dari jumlah tersebut, 60\% gurunya berusia antara 21-30 tahun dan 40\% berusia antara 41-50 tahun. Hal ini menunjukkan bahwa bidang ini didominasi oleh guru angkatan muda sehingga diharapkan dapat lebih 


\section{Vol. 1 No. 4 Oktober 2021 e-ISSN : 2774-6283 | p-ISSN : 2775-0019}

memacu kreatifitas peserta didik serta terjalinnya komunikasi dan hubungan yang baik karena perbedaan usia antara guru dan peserta didik tidak terlalu jauh.

3. Struktur Ekonomi Kota Pontianak

Dilihat dari struktur yang ada berdasarkan 9 (sembilan) sektor lapangan usaha pada tahun 2004 sektor perdagangan, restoran \& hotel mempunyai kontribusi yang paling tinggi dalam kegiatan perekonomian sebesar 22,06 \% sedangkan untuk sektor listrik, gas dan air bersih adalah yang rendah dimana kontribusinya hanya sebesar $0,59 \%$. Untuk tahun 2008 sektor perdagangan, restoran dan hotel masih menjadi penyumbang tertinggi dalam memberikan kontribusinya dalam struktur ekonomi Kota Pontianak dengan kontribusi sebesar 22,63\% sedangkan sektor yang paling rendah dari keseluruhan sektor adalah sektor pertanian dimana memberikan kontribusi hanya sebesar $0,54 \%$.

Tabel 4 Struktur Ekonomi Kota Pontianak

\begin{tabular}{|c|c|c|c|c|c|c|}
\hline No. & Lapangan Usaha & 2004 & 2005 & 2006 & 2007 & 2008 \\
\hline 1 & Pertanian & $0,62 \%$ & $0,59 \%$ & $0,56 \%$ & $0,56 \%$ & $0,54 \%$ \\
\hline 2 & Pertambangan \& Penggalian & - & - & - & - & - \\
\hline 3 & Industri Pengolahan & $8,37 \%$ & $8,37 \%$ & $8,50 \%$ & $8,46 \%$ & $8,49 \%$ \\
\hline 4 & Listrik, Gas \& Air Bersih & $0,59 \%$ & $0,59 \%$ & $0,57 \%$ & $0,57 \%$ & $0,57 \%$ \\
\hline 5 & Bangunan & $16,10 \%$ & $16,29 \%$ & $16,34 \%$ & $16,30 \%$ & $16,38 \%$ \\
\hline 6 & $\begin{array}{l}\text { Perdagangan, Restoran \& } \\
\text { Hotel }\end{array}$ & $22,06 \%$ & $22,10 \%$ & $22,21 \%$ & $22,43 \%$ & $22,63 \%$ \\
\hline 7 & Pengangkutan \& Komunikasi & $20,13 \%$ & $20,20 \%$ & $20,14 \%$ & $20,35 \%$ & $20,25 \%$ \\
\hline 8 & $\begin{array}{l}\text { Keuangan, Pers dan Jasa } \\
\text { Perusahaan }\end{array}$ & $10,62 \%$ & $10,71 \%$ & $10,69 \%$ & $10,66 \%$ & $10,58 \%$ \\
\hline \multirow[t]{2}{*}{9} & Jasa-jasa & $21,51 \%$ & $21,15 \%$ & $20,98 \%$ & $20,68 \%$ & $20,57 \%$ \\
\hline & PDRB & $100,00 \%$ & $100,00 \%$ & $100,00 \%$ & $100,00 \%$ & $100,00 \%$ \\
\hline
\end{tabular}

Dalam Rencana Pembangunan Jangka Menengah (RPJM) Kota Pontianak 20102014 pada halaman 12 disebutkan bahwa dalam kurun waktu 6 (enam) tahun kedepan masih didominasi oleh sektor tersier yaitu sektor perdagangan, angkutan, keuangan dan jasa-jasa, sedangkan sektor yang terendah dalam struktur ekonomi Kota Pontianak adalah sektor pertanian yang diperkirakan pada tahun 2014 mengalami penurunan menjadi 0,46 $\%$.

Tabel 5 Struktur Ekonomi Kota Pontianak Tahun 2009 - 2014

\begin{tabular}{|c|c|c|c|c|c|c|c|}
\hline No. & Lapangan Usaha & 2009 & 2010 & 2011 & 2012 & 2013 & 2014 \\
\hline 1 & Pertanian & $0,53 \%$ & $0,51 \%$ & $0,50 \%$ & $0,48 \%$ & $0,47 \%$ & $0,46 \%$ \\
\hline 2 & $\begin{array}{l}\text { Pertambangan \& } \\
\text { Penggalian }\end{array}$ & . & . & & s. & s. & \\
\hline 3 & Industri Pengolahan & $8,46 \%$ & $8,43 \%$ & $8,39 \%$ & $8,35 \%$ & $9,30 \%$ & $8,26 \%$ \\
\hline 4 & $\begin{array}{l}\text { Listrik, Gas \& Air } \\
\text { Bersih }\end{array}$ & $0,57 \%$ & $0,57 \%$ & $0,56 \%$ & $0,56 \%$ & $0,56 \%$ & $0,56 \%$ \\
\hline 5 & Bangunan & $16,45 \%$ & $16,56 \%$ & $16,68 \%$ & $16,78 \%$ & $16,89 \%$ & $16,99 \%$ \\
\hline 6 & $\begin{array}{l}\text { Perdagangan, } \\
\text { Restoran \& Hotel }\end{array}$ & $22,81 \%$ & $23,00 \%$ & $23,19 \%$ & $23,39 \%$ & $23,58 \%$ & $23,76 \%$ \\
\hline 7 & $\begin{array}{l}\text { Pengangkutan \& } \\
\text { Komunikasi }\end{array}$ & $20,22 \%$ & $20,18 \%$ & $20,13 \%$ & $20,10 \%$ & $20,07 \%$ & $20,01 \%$ \\
\hline 8 & $\begin{array}{l}\text { Keuangan, Pers dan } \\
\text { Jasa Perusahaan }\end{array}$ & $10,52 \%$ & $10,44 \%$ & $10,35 \%$ & $10,28 \%$ & $10,20 \%$ & $10,15 \%$ \\
\hline 9 & Jasa-jasa & $20,46 \%$ & $20,32 \%$ & $20,20 \%$ & $20,06 \%$ & $19,93 \%$ & $19,83 \%$ \\
\hline & PDRB & $100 \%$ & $100 \%$ & $100 \%$ & $100 \%$ & $100 \%$ & $100 \%$ \\
\hline
\end{tabular}

Berdasarkan data di atas, kita dapat melihat bahwa pada tahun 2009 sektor perdagangan mengalami koreksi sebesar 22,81 \% kemudian disusul dengan sektor jasa dan 


\section{Vol. 1 No. 4 Oktober 2021 e-ISSN : 2774-6283 | p-ISSN : 2775-0019}

pengangkutan yang masing-masing sebesar 20,46\% dan 20,22 \% sedangkan yang terendah adalah sektor pertanian hanya sebesar $0,53 \%$. Struktur ekonomi Kota Pontianak Tahun 2009 dapat kita jadikan acuan karena ini merupakan tahun terakhir yang sesuai dengan kondisi lapangan.

4. Penyerapan Tenaga Kerja Kota Pontianak

Tingkat penyerapan tenaga kerja pada setiap sektor ekonomi bisa mencerminkan pada sektor ekonomi mana yang paling banyak menyerap tenaga kerja sekaligus mencerminkan bahwa sektor ekonomi tersebut sangat dominan peranannya dalam meningkatkan pendapatan daerah.

Pada tahun 2004 jumlah tenaga kerja yang terserap berdasarkan sektor lapangan kerja sebanyak 211.193 orang. Sebagian besar tenaga kerja terserap di sektor perdagangan, hotel dan restoran sebanyak 101.092 orang, sektor jasa sebanyak 42.956 orang, sektor industri sebanyak 22.665 orang dan sektor pangangkutan/komunikasi sebanyak 16.494 orang. Pada tahun 2008 sektor perdagangan masih mendominasi penyerapan tenaga kerja yaitu sebanyak 125.883 orang, sektor jasa-jasa menyerap sebanyak 45.721 orang, sektor industri sebanyak 21.727 orang dan sektor pengangkutan menyerap tenaga kerja sebanyak 18.733 orang sehingga total penyerapan tenaga kerja seluruhnya mencapai 243.457 orang.

Tabel 6 Penyerapan Tenaga Kerja Kota Pontianak 2004 - 2008

\begin{tabular}{|c|c|c|c|c|c|c|}
\hline No. & Lapangan Usaha & 2004 & 2005 & 2006 & 2007 & 2008 \\
\hline 1 & Pertanian & 8.830 & 8.993 & 9.120 & 9.221 & 9.323 \\
\hline 2 & Pertambangan \& Galian & 132 & 139 & 141 & 145 & 150 \\
\hline 3 & Industri Non Migas & 22.665 & 22.415 & 22.168 & 21.946 & 21.727 \\
\hline 4 & Listrik dan Air Minum & 1.257 & 1.311 & 1.356 & 1.400 & 1.446 \\
\hline 5 & Bangunan & 15.480 & 16.045 & 16.775 & 17.404 & 18.057 \\
\hline 6 & $\begin{array}{l}\text { Perdagangan, Hotel \& } \\
\text { Restoran }\end{array}$ & 101.092 & 105.660 & 112.525 & 118.488 & 125.883 \\
\hline 7 & $\begin{array}{l}\text { Pengangkutan \& } \\
\text { Komunikasi }\end{array}$ & 16.494 & 16.553 & 17.613 & 18.165 & 18.733 \\
\hline 8 & $\begin{array}{l}\text { Keuangan, Persewaan dan } \\
\text { Jasa Perusahaan }\end{array}$ & 2.287 & 2.313 & 2.344 & 2.379 & 2.416 \\
\hline \multirow[t]{2}{*}{9} & Jasa-jasa & 42.956 & 43.870 & 44.345 & 45.090 & 45.721 \\
\hline & Jumlah & 211.193 & 217.300 & 226.388 & 234.239 & 243.457 \\
\hline
\end{tabular}

Dalam Rencana Pembangunan Jangka Menengah (RPJM) Kota Pontianak 20102014 pada halaman 12 disebutkan bahwa berdasarkan hasil analisis, penyerapan tenaga kerja setiap tahunnya mengalami peningkatan dimana pada tahun 2009 jumlah keseluruhan mencapai 256.494 orang meningkat menjadi 270.494 orang di tahun 2010 sedangkan untuk tahun 2014 diperkirakan akan mencapai 337.033 orang.

Tabel 7. Penyerapan Tenaga Kerja Kota Pontianak 2009 - 2014

\begin{tabular}{|c|c|c|c|c|c|c|c|}
\hline No. & Lapangan Usaha & 2009 & 2010 & 2011 & 2012 & 2013 & 2014 \\
\hline 1 & Pertanian & 9.560 & 9.796 & 10.044 & 10.300 & 10.565 & 10.840 \\
\hline 2 & $\begin{array}{l}\text { Pertambangan \& } \\
\text { Galian }\end{array}$ & 156 & 161 & 169 & 175 & 180 & 186 \\
\hline 3 & Industri Non Migas & 22.769 & 23.874 & 25.034 & 26.258 & 27.545 & 28.922 \\
\hline 4 & $\begin{array}{l}\text { Listrik \& Air } \\
\text { Minum }\end{array}$ & 1.515 & 1.588 & 1.665 & 1.748 & 1.836 & 1.929 \\
\hline 5 & Bangunan & 19.066 & 20.212 & 21.431 & 22.734 & 24.125 & 25.621 \\
\hline 6 & $\begin{array}{l}\text { Perdagangan, Hotel } \\
\text { \& Restoran }\end{array}$ & 133.435 & 141.575 & 150.353 & 159.810 & 169.974 & 180.767 \\
\hline
\end{tabular}


Vol. 1 No. 4 Oktober 2021 e-ISSN : 2774-6283 | p-ISSN : 2775-0019

$\begin{array}{llrrrrrr}7 & \begin{array}{l}\text { Pengangkutan \& } \\ \text { Komunikasi }\end{array} & 19.669 & 20.659 & 21.710 & 22.839 & 24.061 & 25.324 \\ 8 & \text { Keu, Pers dan Jasa } & 2.523 & 2.636 & 2.574 & 2.881 & 3.016 & 3.168 \\ 9 & \text { Pershaan } & 47.801 & 49.990 & 52.315 & 54.773 & 57.403 & 60.273 \\ \text { Jasa-jasa } & \mathbf{2 5 6 . 4 9 4} & \mathbf{2 7 0 . 4 9 4} & \mathbf{2 8 5 . 4 7 9} & \mathbf{3 0 1 . 5 2 3} & \mathbf{3 1 8 . 7 0 8} & \mathbf{3 3 7 . 0 3 3}\end{array}$

Berdasarkan data di atas, kita dapat melihat bahwa jumlah penyerapan tenaga kerja dari 9 (sembilan) sektor lapangan usaha yang ada, sektor perdagangan, hotel dan restoran merupakan sektor yang paling banyak menyerap tenaga kerja. Hal ini dapat dilihat dari jumlah sektor ini pada tahun 2009 mencapai 133.435 tenaga kerja dan diperkirakan meningkat menjadi 180.767 tenaga kerja pada tahun 2014. Jumlah penyerapan tenaga kerja Kota Pontianak Tahun 2009 dapat kita jadikan acuan karena ini merupakan tahun terakhir yang sesuai dengan kondisi lapangan.

\section{Pembahasan}

Sekolah menengah kejuruan (SMK) sebagai bentuk satuan pendidikan kejuruan sebagaimana ditegaskan dalam penjelasan Pasal 15 UU No.20 Tahun 2003 tentang SISDIKNAS, merupakan pendidikan menengah yang mempersiapkan peserta didik terutama untuk bekerja dalam bidang tertentu.

Oleh karena itu, keberadaan SMK di suatu daerah harus disesuaikan dengan kondisi ekonomi serta jumlah tenaga kerja yang dibutuhkan. Hal ini dilakukan untuk menentukan jenis bidang studi keahlian yang akan dikembangkan pada suatu daerah disesuaikan dengan karakteristik wilayah yang dimiliki oleh daerah tersebut, sehingga nantinya lulusan SMK benarbenar dibutuhkan oleh dunia kerja.

Faktor lain yang harus diperhatikan dalam mengembangkan SMK di suatu wilayah adalah ketersediaan guru terutama guru produktif sebagai penunjang kegiatan pembelaran. Untuk itulah, penulis melakukan analisis khususnya terhadap dua faktor tersebut, yaitu kesesuaian potensi wilayah yang dimiliki dengan bidang studi keahlian SMK yang dikembangkan serta menganalisa prediksi kebutuhan guru produktif.

1. Kesesuaian Antara Potensi Kota Pontianak dengan Bidang Studi Keahlian SMK yang dikembangkan

Kota Pontianak sebagai ibukota provinsi Kalimantan Barat merupakan barometer perkembangan kota-kota lain di provinsi tersebut. Berdasarkan tabel 4 dan tabel 5 tentang struktur ekonomi Kota Pontianak, didapati bahwa sektor Perdagangan, restoran dan hotel menempati urutan tertinggi sepanjang tahun 2004 hingga 2009. Perkembangan persentase sektor ini dapat digambarkan pada grafik berikut:

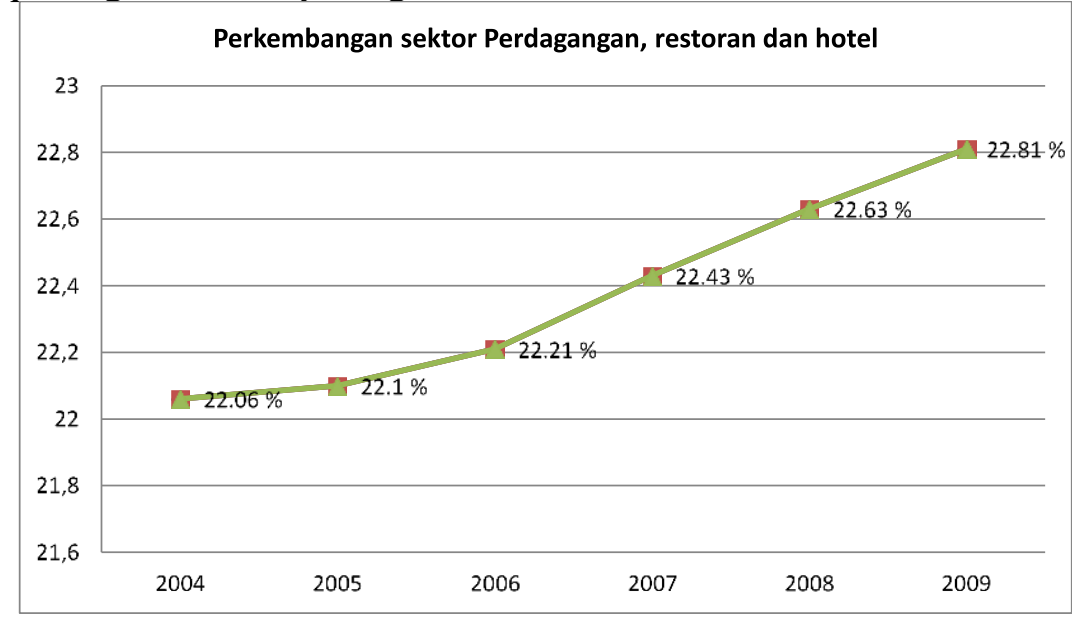

Gambar 1 Grafik Perkembangan Sektor perdagangan, restoran dan hotel Kota Pontianak 


\section{Vol. 1 No. 4 Oktober 2021 e-ISSN : 2774-6283 | p-ISSN : 2775-0019}

Dari grafik di atas didapati bahwa pada tahun 2004 persentase sektor perdagangan, restoran dan hotel mencapai angka 22,06 \%, kemudian pada tahun-tahun berikutnya terus mengalami peningkatan hingga pada tahun 2009 mencapai 22,81\%. Hal ini menandakan bahwa sektor perdagangan, restoran dan hotel merupakan sektor tertinggi dalam struktur ekonomi Kota Pontianak. Selain itu, pada sektor ini juga menunjukkan ada peningkatan tiap tahunnya. Data ini juga diperkuat oleh penelitian E. Julianti dan S. Martha yang diterbitkan dalam Jurnal Penelitian Buletin Ilmiah Mat. Stat. dan terapannya Volume 05 No. 1 Tahun 2016, hal. 19-24, yang menyatakan bahwa berdasarkan Analisis Location Quotient sector ekonomi ini memiliki nilai LQ > 1 yang artinya menandakan bahwa sector ini merupakan sector basis dari perekonomian Kota Pontianak.

Ditinjau dari aspek penyerapan tenaga kerja, sektor perdagangan, restoran dan hotel juga menempati urutan pertama dan menjadi penyerap tenaga kerja terbanyak. Berdasarkan tabel 4.8 dan tabel 4.9 tentang penyerapan tenaga kerja Kota Pontianak, didapati bahwa sektor perdagangan, restoran dan hotel menjadi penyumpang penyerap tenaga kerja tertinggi dengan jumlah 101.092 orang tenaga kerja pada tahun 2004. Dominasi ini berlajut hingga tahun 2009 yang mampu menyerap tenaga kerja tertinggi sebanyak 133.435 orang. Perkembangan jumlah tenaga kerja yang mampu diserap oleh sektor ini dari tahun 2004 sampai 2009 dapat digambarkan melalui grafik berikut:

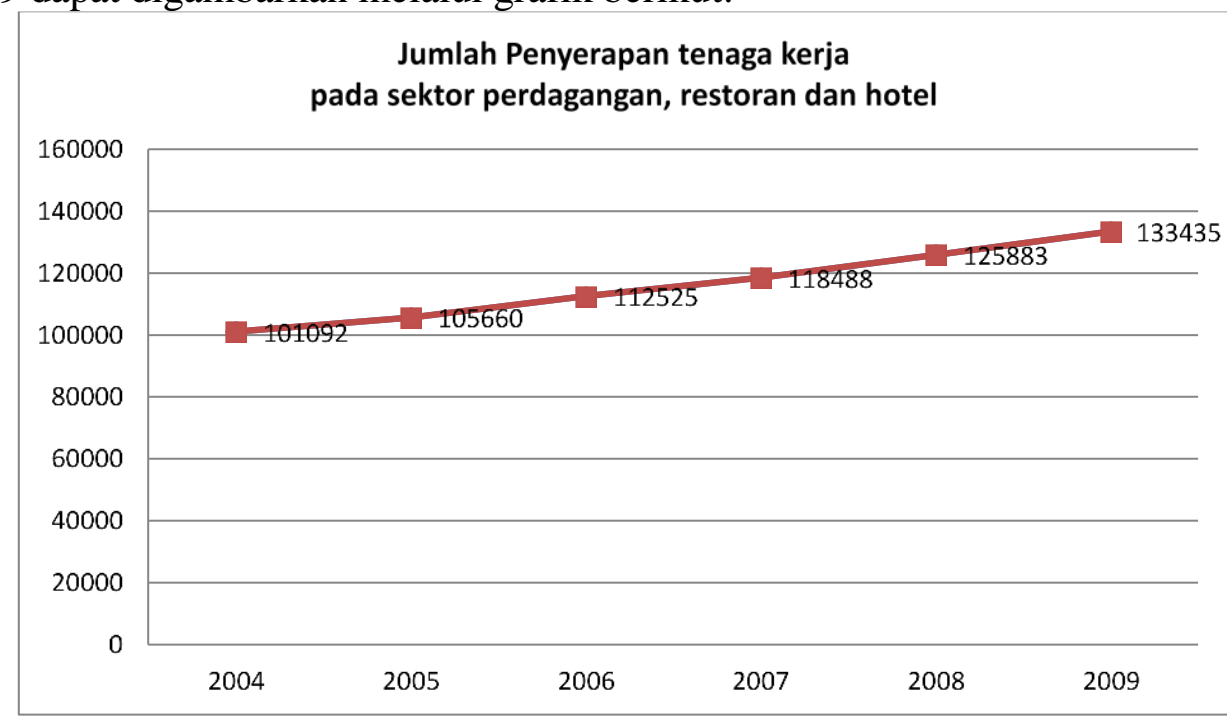

\section{Gambar 2. Grafik Jumlah Penyerapan tenaga kerja Sektor perdagangan, restoran dan hotel di Kota Pontianak}

Dari grafik di atas didapati bahwa pada tahun 2004 jumlah tenaga kerja sektor perdagangan, restoran dan hotel mencapai 101.092 orang, kemudian pada tahun-tahun berikutnya terus mengalami peningkatan hingga pada tahun 2009 mencapai 133.435 orang. Hal ini menandakan bahwa sektor perdagangan, restoran dan hotel merupakan sektor tertinggi dalam penyerapan tenaga kerja. Selain itu, pada sektor ini juga menunjukkan ada peningkatan tiap tahunnya.

Berdasarkan uraian di atas, dapat kita ambil kesimpulan bahwa sektor perdagangan, restoran dan hotel merupakan sektor yang paling tinggi dan dominan dalam struktur ekonomi Kota Pontianak $(22,81 \%)$. Selain itu sektor ini pula yang paling banyak menyerap tenaga kerja yaitu sebanyak 133.435 orang pada tahun 2009 (52,02\% dari total tenaga kerja yang diserap pada tahun tersebut).

Berdasarkan pembagian Bidang Keahlian SMK yang tertuang dalam SK Direktur Jenderal manajemen Pendidikan Dasar dan Menengah nomor 251/C/KEP/MN/2008 tentang spektrum keahlian pendidikan menengah kejuruan, sektor Perdagangan, restoran dan hotel dapat kita kelompokkan pada Bidang Studi Keahlian Seni, Kerajinan dan Pariwisata. 


\section{Vol. 1 No. 4 Oktober 2021 e-ISSN : 2774-6283 | p-ISSN : 2775-0019}

Sehingga, berdasarkan struktur ekonomi dan jumlah penyerapan tenaga kerja yang sudah penulis uraikan di atas, maka jenis SMK yang harus dikembangkan di Kota Pontianak adalah SMK dengan bidang keahlian Seni, Kerajinan dan Pariwisata.

Bila kita tinjau kembali jumlah bidang keahlian SMK yang dikembangkan di Kota Pontianak, sebagaimana yang tertera pada gambar diagram 4.1, maka jenis SMK yang ada di Kota Pontianak belum sesuai dengan karakteristik wilayah yang dimiliki karena Bidang Studi Keahlian Seni, Kerajinan dan Pariwisata baru dikembangkan di 4 sekolah atau hanya sekitar $12 \%$, kalah jauh dengan bidang studi keahlian Bisnis dan Manajemen yang sudah dikembangkan sebesar $37 \%$.

Sehingga bisa kita ambil kesimpulan bahwa pengembangan SMK di Kota Pontianak belum sejalan dengan karakteristik wilayah yang dimiliki. Hal ini harus menjadi perhatian yang serius. Hal ini perlu menjadi perhatian serius agar tidak terjadi penumpukan lulusan karena ketidaksesuaian kompetensi dengan dunia kerja yang sedang berkembang, konsekuensinya akan menimbulkan penggangguran dan secara tidak langsung berdampak pada terhambatnya pembangunan nasional.

2. Kebutuhan Guru ditinjau dari proporsi kegiatan perekonomian Kota Pontianak

Sebagaimana telah penulis jelaskan pada uraian di atas, bahwa berdasarkan analisis data yang dilakukan, SMK yang menjadi prioritas untuk dikembangkan di Kota Pontianak adalah SMK dengan bidang studi keahlian Seni, Kerajinan dan Pariwisata. Hal ini sesuai dengan kegiatan perekonomian dan penyerapan tenaga kerja yang terjadi di Kota Pontianak. Sekarang, tibalah saatnya untuk menganalisa kebutuhan guru produktif untuk seluruh bidang studi keahlian yang dikembangkan di Kota Pontianak.

Penulis melakukan pengelompokan sekolah berdasarkan sektor penunjang perekonomian. Hal ini bertujuan untuk melihat sektor perekonomian mana yang ditunjang oleh masing-masing bidang studi keahlian yang dikembangkan. Selanjutnya, penulis menentukan jumlah rombel yang ideal untuk masing-masing bidang studi keahlian berdasarkan persentase sektor kegiatan perekonomian.

Tabel 8. Pengelompokkan Sekolah Berdasarkan Sektor Penunjang Perekonomian

\begin{tabular}{ll}
\hline \multicolumn{1}{c}{ Penyuplai (Sekolah) } & \multicolumn{1}{c}{ Yang Disuplai (Sektor) } \\
\hline SMK Bisnis dan Manajemen (BM) & Keuangan, Persewaan dan Jasa \\
& Perusahaan (KPJP) \\
& Listrik, Gas dan Air Bersih \\
(LGAB) & Industri Pengolahan (IP) \\
SMK Teknologi dan Rekayasa (TR) & Bangunan (BG) \\
& $\begin{array}{l}\text { Pengangkutan dan Komunikasi } \\
\text { SMK Teknologi Informasi dan Komunikasi (TIK) }\end{array}$ \\
& PK) \\
SMK Seni, Kerajinan dan Pariwisata (SKP) & (PHR) \\
SMK Agribisnis dan Agroteknologi (2A) & Pertanian (PT) \\
SMK Kesehatan (KS) & Jasa - jasa (2J) \\
\hline
\end{tabular}

Tabel 9. Proporsi Rombel Tiap Bidang Keahlian SMK Terhadap Sektor Perekonomian $2009-2010$

\begin{tabular}{llcc}
\hline \multicolumn{1}{c}{$\begin{array}{c}\text { Sektor Yang } \\
\text { Disuplai }\end{array}$} & \multicolumn{1}{c}{$\begin{array}{c}\text { Persentase Saat Ini } \\
\text { (dibulatkan) }\end{array}$} & $\begin{array}{c}\text { Jml Rombel } \\
\text { Saat Ini }\end{array}$ & Penyuplai \\
\hline KPJP & $10,52=\mathbf{1 0 , 5}$ & 131 & BM \\
LGAB + IP + BG & $0,57+8,46+16,45=\mathbf{2 5 , 5}$ & 100 & TR \\
PK & $20,22=\mathbf{2 0 , 2}$ & 33 & TIK \\
PHR & $22,81=\mathbf{2 2 , 8}$ & 39 & SKP \\
\hline
\end{tabular}


VOCATIONAL : Jurnal Inovasi Pendidikan Kejuruan

Vol. 1 No. 4 Oktober 2021 e-ISSN : 2774-6283 | p-ISSN : 2775-0019

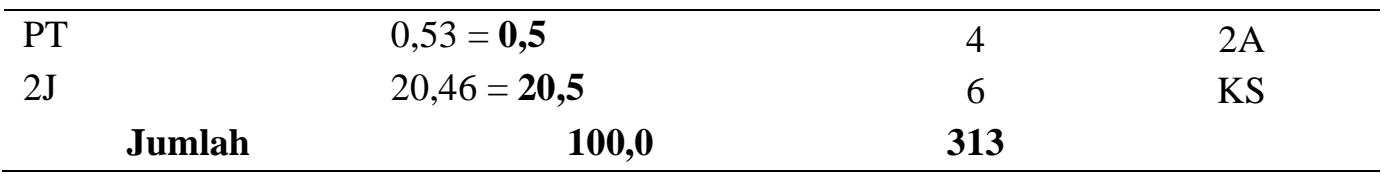

Dengan mengasumsikan jumlah rombel saat ini tetap, maka didapat :

Tabel 10. Proporsi Rombel Tiap Bidang Keahlian SMK yang seharusnya Terhadap Sektor Perekonomian

\begin{tabular}{lccc}
\hline $\begin{array}{c}\text { Sektor Yang } \\
\text { Disuplai }\end{array}$ & Nilai Persentase & $\begin{array}{c}\text { Jml Rombel } \\
\text { Seharusnya }\end{array}$ & Penyuplai \\
\hline KPJP & 10,5 & 33 & BM \\
LGAB + IP + BG & 25,5 & 80 & TR \\
PK & 20,2 & 63 & TIK \\
PHR & 22,8 & 71 & SKP \\
PT & 0,5 & 2 & $2 \mathrm{~A}$ \\
2J $\quad$ Jumlah & 20,5 & 64 & KS \\
\multicolumn{1}{c}{$\quad \mathbf{1 0 0 , 0}$} & $\mathbf{3 1 3}$ & \\
\hline
\end{tabular}

Kemudian dengan menggunakan rumus perhitungan kebutuhan guru produktif: $K G / S=$ Rombel Sekolah $x \frac{32}{24}$ (Guru Produktif) maka didapat kebutuhan guru :

Tabel 11. Kebutuhan Guru Produktif Berdasarkan Jumlah Rombel

\begin{tabular}{lcc}
\hline \multicolumn{1}{c}{ Bidang Keahlian SMK } & Jml Rombel* & Kebutuhan Guru Prod. \\
\hline Bisnis dan Manajemen & 33 & 44 \\
Teknologi dan Rekayasa & 80 & 107 \\
Teknologi Informasi dan Komunikasi & 63 & 84 \\
Seni, Kerajinan dan Pariwisata & 71 & 95 \\
Agribisnis dan Agroteknologi & 2 & 3 \\
Kesehatan & 64 & 85 \\
Jumlah & $\mathbf{3 1 3}$ & $\mathbf{4 1 8}$ \\
\hline
\end{tabular}

Ket: *) Jumlah rombel yang seharusnya terhadap persentase sektor perekonomian

3. Kebutuhan Guru Bidang Produktif Berdasarkan Kebutuhan Jumlah Guru Yang Ideal dan Yang Pensiun Pada Tahun Berjalan

Analisis pada faktor ini diharapkan dapat melihat kebutuhan guru yang ideal untuk menyelenggarakan suatu pendidikan SMK yang berkualitas berdasarkan besar rombel dan membandingkan jumlah guru yang ada pada saat ini serta memperhitungkan jumlah tenaga guru yang akan pensiun. Dengan menggunakan data riil yang diambil dan dengan menggunakan rumus yang sama, maka rekapitulasi kebutuhan guru produktif SMK untuk masing-masing bidang studi keahlian adalah sebagai berikut :

Tabel 12. Rekapitulasi Kebutuhan Guru Produktif Tiap Sekolah Pada SMK Bisnis dan Manajemen di Kota Pontianak

\begin{tabular}{|c|c|c|c|c|c|c|}
\hline No & Nama SMK & $\begin{array}{l}\text { Jumlah } \\
\text { Rombel } \\
\text { (I,II,III) }\end{array}$ & Ket* & $\begin{array}{c}\text { KG / S } \\
\text { Ideal }\end{array}$ & $\begin{array}{c}\text { KG / S } \\
\text { Yang } \\
\text { Ada }\end{array}$ & $\begin{array}{c}\text { Guru yang } \\
\text { Diperlukan } \\
(-/+)\end{array}$ \\
\hline 1 & SMK Negeri 3 Kota Pontianak & 25 & & 33 & 27 & +6 \\
\hline 2 & SMK Ethika Kota Pontianak & 3 & & 4 & 6 & -2 \\
\hline 3 & SMK Koperasi Kota Pontianak & 8 & & 11 & 8 & +3 \\
\hline 4 & SMK Bhineka Tunggal Ika & 6 & & 8 & 5 & +3 \\
\hline 5 & SMK LKIA Kota Pontianak & 17 & & 23 & 10 & +13 \\
\hline 6 & SMK Santa Maria & 6 & & 8 & 5 & +3 \\
\hline 7 & SMK Immanuel Kota Pontianak & 9 & & 12 & 8 & +4 \\
\hline 8 & SMK Muhammadiyah & 8 & & 11 & 10 & +1 \\
\hline
\end{tabular}


Vol. 1 No. 4 Oktober 2021 e-ISSN : 2774-6283 | p-ISSN : 2775-0019

$\begin{array}{clcccc}9 & \text { SMK Mandiri Kota Pontianak } & 15 & 20 & 12 & +8 \\ 10 & \text { SMK Boedi Oetomo } & 3 & 4 & 5 & -1 \\ 11 & \text { SMK Abdi Agape Kota Pontianak } & 10 & 13 & 9 & +4 \\ 12 & \text { SMK Negeri 1 Kota Pontianak } & 21 & 28 & 20 & +8 \\ & \text { Jumlah } & \mathbf{1 3 1} & \mathbf{1 7 5} & \mathbf{1 2 5} & \mathbf{5 0}\end{array}$

Jumlah guru yang akan pensiun (rentang usia > 50 tahun) pada bidang studi keahlian ini berjumlah 13 orang, jadi total kebutuhan guru yang diperlukan agar sesuai kebutuhan sebanyak 63 orang.

Tabel 13 Rekapitulasi Kebutuhan Guru Produktif Tiap Sekolah Pada SMK Teknologi dan Rekayasa di Kota Pontianak

\begin{tabular}{|c|c|c|c|c|c|c|}
\hline No & Nama SMK & $\begin{array}{l}\text { Jumlah } \\
\text { Rombel } \\
\text { (I,II,III) }\end{array}$ & Ket* & $\begin{array}{c}\text { KG / S } \\
\text { Ideal }\end{array}$ & $\begin{array}{c}\text { KG / S } \\
\text { Yang } \\
\text { Ada }\end{array}$ & $\begin{array}{c}\text { Guru yang } \\
\text { Diperlukan } \\
(-/+)\end{array}$ \\
\hline 1 & SMK PGRI Kota Pontianak & 10 & & 13 & 11 & +2 \\
\hline 2 & SMK Negeri 4 Kota Pontianak & 39 & & 52 & 16 & +36 \\
\hline 3 & SMK Negeri 2 Kota Pontianak & 21 & & 28 & 24 & +4 \\
\hline 4 & SMTI Kota Pontianak & 6 & & 8 & 8 & 0 \\
\hline 5 & SMK Bina Utama Kota Pontianak & 15 & & 20 & 16 & +4 \\
\hline 6 & SMK Negeri 7 Kota Pontianak & 3 & & 4 & 3 & +1 \\
\hline 7 & SMK Pelayaran Pembangunan & 3 & & 4 & 8 & -4 \\
\hline \multirow[t]{2}{*}{8} & SMK Sultan Syarif Abdurrahman & 3 & & 4 & 4 & 0 \\
\hline & Jumlah & 34 & & 133 & 90 & 43 \\
\hline
\end{tabular}

Jumlah guru yang akan pensiun (rentang usia > 50 tahun) pada bidang studi keahlian ini berjumlah 8 orang, jadi total kebutuhan guru yang diperlukan agar sesuai kebutuhan sebanyak 51 orang.

Tabel 14 Rekapitulasi Kebutuhan Guru Produktif Tiap Sekolah Pada SMK Seni, Kerajinan dan Pariwisata di Kota Pontianak

\begin{tabular}{|c|c|c|c|c|c|c|}
\hline No & Nama SMK & $\begin{array}{l}\text { Jumlah } \\
\text { Rombel } \\
\text { (I,II,III) } \\
\end{array}$ & Ket* & $\begin{array}{c}\text { KG / S } \\
\text { Ideal }\end{array}$ & $\begin{array}{c}\text { KG / S } \\
\text { Yang } \\
\text { Ada }\end{array}$ & $\begin{array}{c}\text { Guru yang } \\
\text { Diperlukan } \\
(-/+)\end{array}$ \\
\hline 1 & SMK Negeri 6 Kota Pontianak & 12 & & 16 & 24 & -8 \\
\hline 2 & SMK Cinta Bumi Khatulistiwa & 7 & & 9 & 6 & +3 \\
\hline 3 & SMK Negeri 5 Kota Pontianak & 17 & & 23 & 23 & 0 \\
\hline \multirow[t]{2}{*}{4} & SMK Negeri 1 Kota Pontianak & 3 & & 4 & 6 & -2 \\
\hline & Jumlah & 39 & & 52 & 59 & -7 \\
\hline
\end{tabular}

Berdasarkan perhitungan dengan menyesuaikan terhadap kondisi perekonomian, didapati bahwa guru bidang produktif pada bidang studi keahlian Seni, Kerajinan dan Pariwisata mengalami kelebihan guru sebanyak 7 orang. Akan tetapi, guru yang akan pensiun (rentang usia $>50$ tahun) pada bidang ini mencapai 8 orang. Sehingga masih dibutuhkan tambahan 1 orang guru produktif pada bidang studi keahlian ini.

Tabel 15 Rekapitulasi Kebutuhan Guru Produktif Tiap Sekolah Pada SMK Teknologi Informasi dan Komunikasi di Kota Pontianak

\begin{tabular}{|c|c|c|c|c|c|c|}
\hline No & Nama SMK & $\begin{array}{l}\text { Jumlah } \\
\text { Rombel } \\
\text { (I,II,III) }\end{array}$ & Ket* & $\begin{array}{c}\text { KG / S } \\
\text { Ideal }\end{array}$ & $\begin{array}{c}\text { KG / S } \\
\text { Yang } \\
\text { Ada }\end{array}$ & $\begin{array}{c}\text { Guru yang } \\
\text { Diperlukan } \\
(-/+) \\
\end{array}$ \\
\hline 1 & SMK Negeri 6 Kota Pontianak & 3 & & 4 & 7 & -3 \\
\hline 2 & SMK Negeri 4 Kota Pontianak & 5 & & 7 & 2 & +5 \\
\hline 3 & SMK Al-Madani Kota Pontianak & 7 & & 9 & 2 & +7 \\
\hline 4 & SMK Koperasi Kota Pontianak & 2 & & 3 & 2 & +1 \\
\hline 5 & SMK Immanuel Kota Pontianak & 6 & & 8 & 5 & +3 \\
\hline 6 & SMK Negeri 7 Kota Pontianak & 7 & & 9 & 6 & +3 \\
\hline \multirow[t]{2}{*}{7} & SMK Sultan Syarif Abdurrahman & 3 & & 4 & 3 & +1 \\
\hline & Jumlah & 33 & & 44 & 27 & 17 \\
\hline
\end{tabular}


Dengan melihat hasil perhitungan dari tabel diatas, maka disimpulkan dibutuhkan penambahan sebanyak 17 orang guru pada bidang keahlian Teknologi Informasi dan Komunikasi untuk mencapai jumlah yang ideal dan sesuai dengan standar pendidikan nasional dan untuk menghasilkan efektifitas dari proses belajar mengajar.

Tabel 16 Rekapitulasi Kebutuhan Guru Produktif Tiap Sekolah Pada SMK Kesehatan di Kota Pontianak

\begin{tabular}{|c|c|c|c|c|c|c|}
\hline No & Nama SMK & $\begin{array}{l}\text { Jumlah } \\
\text { Rombel } \\
\text { (I,II,III) }\end{array}$ & Ket* & $\begin{array}{c}\text { KG / S } \\
\text { Ideal }\end{array}$ & $\begin{array}{c}\text { KG / S } \\
\text { Yang } \\
\text { Ada }\end{array}$ & $\begin{array}{c}\text { Guru yang } \\
\text { Diperlukan } \\
(-/+)\end{array}$ \\
\hline 1 & SMTI Kota Pontianak & 6 & & 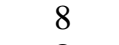 & 8 & 0 \\
\hline & Jumlah & 6 & & 8 & 8 & $\mathbf{0}$ \\
\hline
\end{tabular}

Berdasarkan perhitungan pada tabel di atas, maka jumlah guru produktif untuk bidang studi keahlian kesehatan sudah ideal. Akan tetapi, ada sejumlah guru yang akan pensiun (rentang usia $>50$ tahun) pada bidang ini mencapai 2 orang.

\begin{tabular}{|c|c|c|c|c|c|c|}
\hline No & Nama SMK & $\begin{array}{l}\text { Jumlah } \\
\text { Rombel } \\
\text { (I,II,III) }\end{array}$ & Ket* & $\begin{array}{c}\text { KG / S } \\
\text { Ideal }\end{array}$ & $\begin{array}{c}\text { KG / S } \\
\text { Yang } \\
\text { Ada }\end{array}$ & $\begin{array}{c}\text { Guru yang } \\
\text { Diperlukan } \\
(-/+)\end{array}$ \\
\hline 1 & SMK Elim Kalimantan & $\begin{array}{l}4 \\
4\end{array}$ & & $\begin{array}{l}5 \\
5\end{array}$ & $\begin{array}{l}5 \\
5\end{array}$ & $\begin{array}{l}0 \\
\mathbf{0}\end{array}$ \\
\hline
\end{tabular}

Berdasarkan perhitungan pada tabel di atas, maka jumlah guru produktif untuk bidang studi keahlian kesehatan sudah ideal.

Keterangan :

-/+ : Tanda (-) artinya harus ada pengurangan guru, sedangkan tanda (+) harus ada penambahan guru. Jika (0) guru yang ada sudah sesuai kebutuhan.

\section{KESIMPULAN}

Kota Pontianak memiliki 25 SMK yang terdiri atas 7 SMK Negeri dan 18 SMK Swasta. Bidang studi keahlian yang dikembangkan di SMK Kota Pontianak ada 6 yaitu bidang keahlian Bisnis dan Manjemen, bidang keahlian Teknologi dan Rekayasa, bidang keahlian Seni, kerajinan dan pariwisata, bidang keahlian Teknologi Informasi dan Komunikasi, bidang keahlian Agrobisnis dan Agroteknologi, dan yang terakhir bidang keahlian Kesehatan.

Bidang studi keahlian SMK yang ada di Kota Pontianak didominasi oleh bidang keahlian bisnis dan manajemen yang di selenggarakan 12 sekolah atau sebesar 37\%. Diikuti oleh bidang studi keahlian teknologi dan rekayasa diselenggarakan di 8 sekolah, kemudian bidang studi keahlian teknologi informasi dan komunikasi diselenggarakan di 7 sekolah. Bidang studi keahlian seni, kerajinan dan pariwisata diselenggarakan di 4 sekolah, dan sisanya adalah bidang studi keahlian kesehatan yang diselenggarakan di 1 sekolah, serta bidang studi keahlian agrobisnis dan agroteknologi yang juga diselenggarakan di 1 sekolah.

Ada 3 Sektor ekonomi yang dominan di Kota Pontianak yaitu sektor perdagangan, restoran dan hotel dengan persentase sebesar $22,81 \%$, jasa sebesar $20,46 \%$ dan pengangkutan $\&$ komunikasi dengan persentase $20,22 \%$. Kondisi ini belum sesuai dengan bidang keahlian SMK yang paling banyak dikembangkan di Kota Pontianak, yaitu bidang keahlian bisnis dan manajemen. Semestinya, bidang studi keahlian yang paling banyak dikembangkan yaitu bidang studi keahlian Seni, Kerajinan dan Pariwisata, karena SMK dengan bidang keahlian ini yang nantinya akan menyuplai tenaga kerja pada sektor perdagangan, restoran dan hotel yang merupakan sektor ekonomi yang paling dominan di Kota Pontianak. Dengan adanya ketidaksesuaian ini, dikhawatirkan terjadinya penumpukan lulusan SMK yang tidak terserap 


\section{Vol. 1 No. 4 Oktober 2021 e-ISSN : 2774-6283 | p-ISSN : 2775-0019}

oleh dunia kerja sehingga menimbulkan pengangguran yang dapat menghambat pembangunan daerah.

Terdapat 314 tenaga guru produktif di seluruh SMK di Kota Pontianak. Dari jumlah tersebut, sekitar 236 guru sudah berijazah S-1, 8 guru sudah berkualifikasi S-2, 37 orang guru masih D-3, dan 33 orang guru teridentifikasi berijazah SLTA.

\section{DAFTAR PUSTAKA}

Badan Perencanaan Pembangunan Daerah (BAPPEDA) Kota Pontianak. Rencana Pembangunan Jangka Menengah (RPJM) Kota Pontianak 2010-2014

Badan Pusat Statistik. 2009. Kota Pontianak Dalam Angka. Jakarta: Badan Pusat Statistik Kota Pontianak

Direktorat Pendidikan Menengah Kejuruan Depdiknas. Kurikulum SMK Edisi 2004.

Iskandar. (2009). Metode Penelitian Kualitatif. Jakarta: Gaung Persada

Julianti, Evi \& Martha, Santika. (2016). Analisis Pertumbuhan Ekonomi Kota Pontianak dengan Metode Location Quotient, Shift Share dan Gravitasi. Buletin Ilmiah Mat. Stat. dan Terapannya (Bimaster) Volume 05 No. 1, hal. 19-24

Kementerian Pendidikan Nasional. Peraturan Pemerintah No. 19 Tahun 2005 Tentang Standar Nasional Pendidikan.

Moleong, Lexy. J. (2009). Metodologi Penelitian Kualitatif. Jakarta : PT. Remaja Rosdakarya Sugiyono. (2008). Metode Penelitian Pendidikan. Bandung : Alfabeta.

Tim Pustaka Merah Putih. (2007). Undang-Undang Sistem Pendidikan Nasional Guru Dan Dosen. Yogyakarta : Pustaka Merah Putih

Undang-undang Republik Indonesia No.20 Tahun 2003 Tentang Sistem Pendidikan Nasional 